\title{
Sediment transport in the Schelde-estuary: a comparison between measurements, transport formula and numerical models
}

\author{
Yves Plancke ${ }^{1}$, Styn Claeys ${ }^{2}$ \\ ${ }^{1}$ Flemish Government, Flanders Hydraulics Research - Yves.Plancke@mow.vlaanderen.be \\ ${ }^{2}$ Flemish Government, Flanders Hydraulics Research - Styn.Claeys@mow.vlaanderen.be
}

\begin{abstract}
The Schelde-estuary serves different estuarine functions and therefore faces managers with multiple challenges: increasing tidal propagation vs. safety against flooding; sedimentation in the navigation channel vs. port accessability; changing dynamics vs. ecology. Within the Flemish-Dutch Long Term Vision for the Schelde-estuary, a 4 year (20142017) research programme was defined, in which 8 topics will be dealt with (e.g. tidal penetration, risk for regime shift, sediment strategies, valueing ecology). Two fundamental tools will be crucial in answering the different questions towards the future management of the estuary: expertise/system understanding and numerical models. At this moment (first year), several projects are ongoing trying to increase the system understanding and improving the state-of-the-art numerical models. Where the numerical models reproduce the hydrodynamics reasonably well, sediment transport and the resulting morphological changes is still a big challenge. Therefore an extensive monitoring campaign was performed in 2014, during which both hydrodynamic and sediment transport measurement were performed in the Schelde-estuary. At more than 10 locations, from the up-estuarine part (Boven-Zeeschelde) to the mouth area (Vlakte van de Raan), measurements were executed over a full tidal cycle (13h). Currents were measured using ADCP, while sediment transport was measured using both direct (Delft Bottle and pump samples) and indirect (OBS, ABS) techniques. This extensive dataset allows an in-depth analysis of the sediment transport processes occuring in the estuary. A comparison will be made with several transport formula (e.g. Bagnold, Engelund-Hansen, Van Rijn, ...). The data will also be used to validate the existing numerical models, allowing a better assesment of the possibilities and limitations of the present numerical models.
\end{abstract}

\section{KEY WORDS}

Sediment transport, measurements, numerical modelling, estuary

\section{THE SCHELDE-ESTUARY}

The Schelde-estuary is a macro-tidal estuary with a length of $180 \mathrm{~km}$ in Flanders and the southern part of the Netherlands (Figure 1). The Vlakte van de Raan ("mondingsgebied") connects the estuary with the North Sea and should be seen as an integral part of the estuary. This part is a shallow water area with several channels. The Vlakte van de Raan (-20 KM to $0 \mathrm{KM}$ ) connects to the Westerschelde (KM 0 to KM 60), which has a multiple channel system, with ebb and flood channels and intertidal sandbars in between. More up-estuary, near the Dutch-Belgian border, the morphological system changes into a single channel system, the Zeeschelde (KM 60 to KM 160).

The estuary is characterised by semi-diurnal tides, causing ebb and flood currents with important sediment transports of both cohesive as non-cohesive sediments. The Schelde-estuary serves different estuarine functions and therefore faces managers with multiple challenges: increasing tidal propagation vs. safety against flooding; sedimentation in the navigation channel vs. port accessability; changing dynamics vs. ecology. Within the Flemish-Dutch Long Term Vision for the Schelde-estuary, a 4 year (2014-2017) research programme was defined, in which 8 topics will be dealt with (e.g. tidal penetration, risk for regime shift, sediment strategies, valueing ecology).

\section{METHODOLOGY}

In order to supply managers with adequate answers, research tools (both expertise/system understanding and numerical models [Peters et al., 2006]) are crucial in answering the different questions. At this moment (first year), several projects are ongoing trying to increase the system understanding and improving the state-of-the-art numerical models. Where the numerical models reproduce the hydrodynamics reasonably well, sediment transport and the resulting morphological changes is still a big challenge. Within the scope of the MONEOS programme [Plancke et al., 2012], discharge and sediment transport measurements are performed at regular basis (going from continuous SPM measurements at several points to yearly sailed transect measurements). In 2014, an additional monitoring campaign was performed, during which both hydrodynamic and sediment transport measurements were performed in the Schelde-estuary. At more than 10 locations measurements were executed over a full tidal cycle (13h): 3 locations at the Vlakte van de Raan, 7 locations at the Zeeschelde and 1 location at the Rupel, a tributary of the Zeeschelde. 


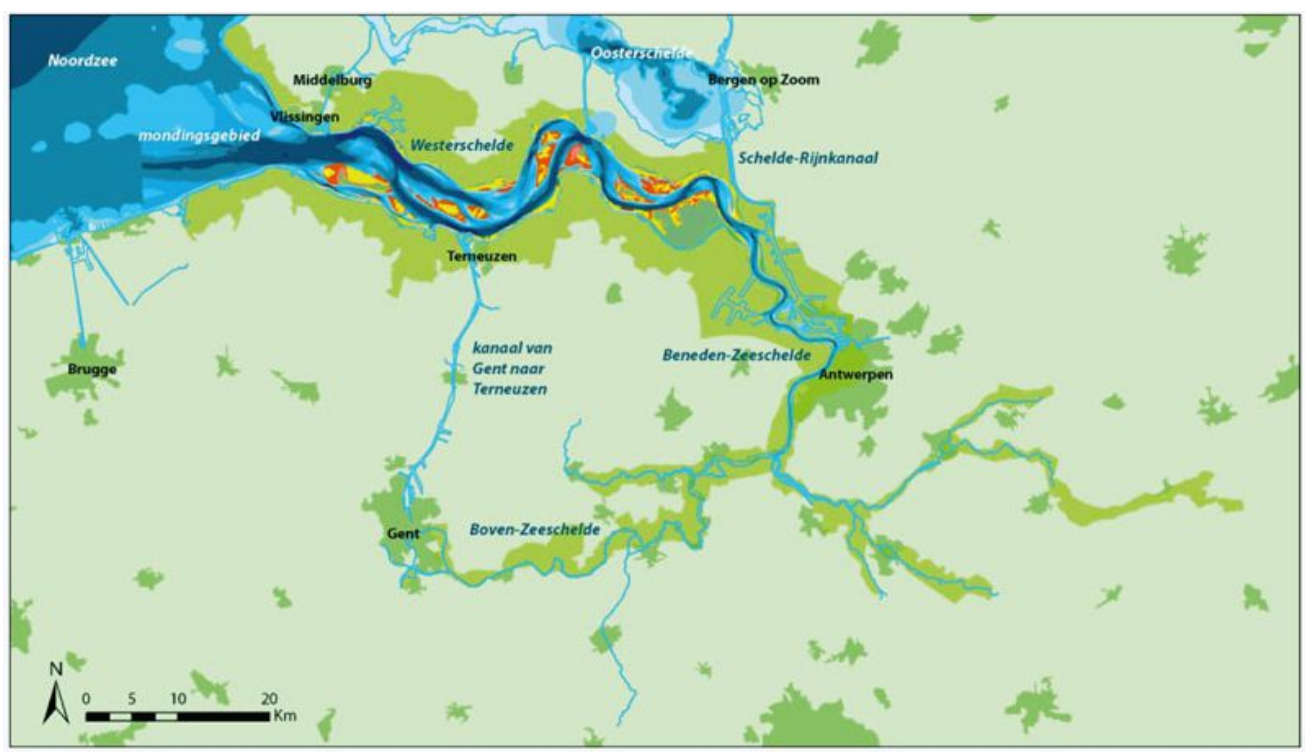

Figure 1 - Overview of the Schelde-estuary (source: http://www.compendiumkustenzee.be)

At each location one or two vessels were used. The first vessel was anchored during the measurement period, performing measurements at a fixed point in the estuary. Currents were measured using ADCP (vertical profile) and Aanderaa Current Meter (point), while sediment transport was measured using both direct (Delft Bottle and pump samples) and indirect (OBS, ABS) techniques. The Delft Bottle technique was used both near-bed (using frame) and in the water column (suspended), at four different positions (bed $+20 \mathrm{~cm}$, bed $+40 \mathrm{~cm}$, bed $+100 \mathrm{~cm}$ and bed $+200 \mathrm{~cm}$ ). Measurements were executed continuously, with sampling times varying from 3 minutes (at peak transport) to 15 minutes (near slack moments). From these measurements total transports were derived every 30 minutes. At those locations where a second vessel was available, additional transects were sailed using ADCP (current and sediment transport from ADCP-backscatter). For the locations at the Vlakte van de Raan, additional frames were placed at the bed, allowing long term (4 weeks) measurements of hydrodynamics (currents and waves) and sediment transport.

The measurements are used to validate the available numerical models. A first project deals with large scale sediment management issues in the down-estuarine part, Vlakte van de Raan (see Van der Werf et al., 2015). A second project focusses on management strategies for the most up-estuarine part, Boven-Zeeschelde (see Maximova et al., 2015). A third project will detail the future sediment strategy in the Beneden-Zeeschelde. Both Delft3D as TELEMAC models are used in these different studies. For the last project a detailed model of the study area has been set up. At this moment, the model is being validated for the sediment transport in the BenedeZeeschelde.

\section{FIELD MEASUREMENTS: RESULTS}

Figure 1 shows the hydrodynamic conditions for the different locations in the Zeeschelde. The tidal characteristics change significantly along the estuary: the most down-estuarine locations of the Zeeschelde (Liefkenshoek, Oosterweel) have an almost symmetrical tide; more up-estuary the tidal asymmetry increases, most pronounced at Schellebelle and Schoonaarde. The tidal range increases from the North Sea up to Driegoten due to the funnel shape of the estuary. More up-estaury it decreases due to the damping effect of the undeeper channels. The asymmetry in the vertical tide is translated into the horizontal tide (flow velocities), with a longer ebb-phase and lower flow velocities more up-estuary. Highest flow velocities are found at Oosterweel (ebb and flood phase) and Driegoten (flood phase).
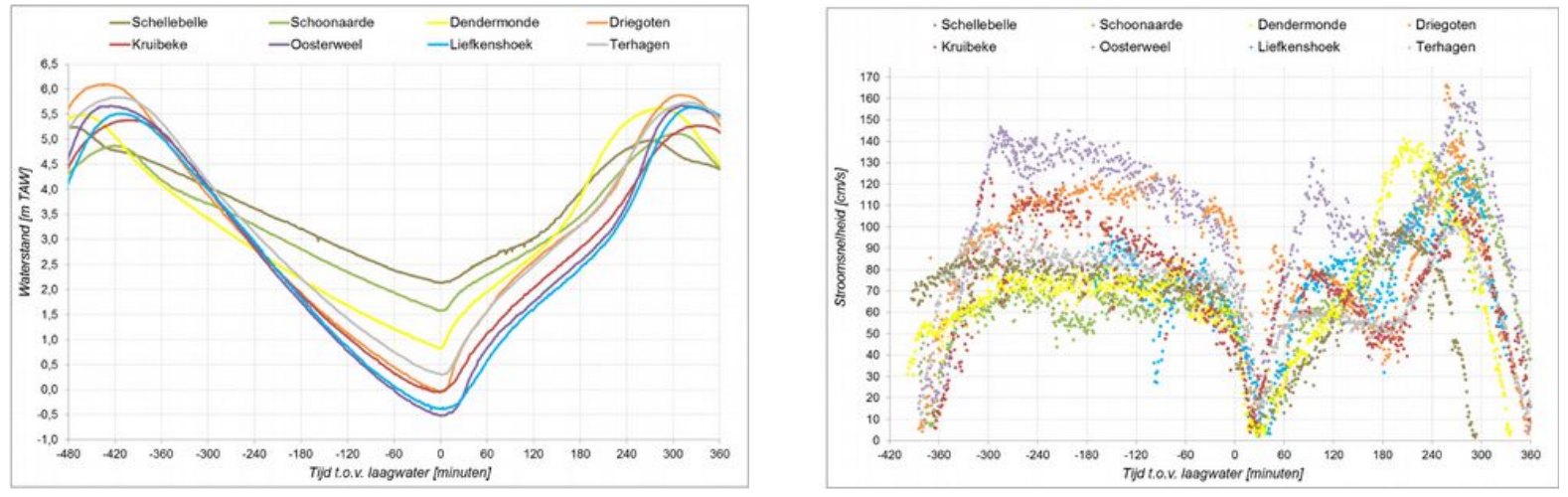

Figure 2 - Overview of tides (left) and flow velocities (right) for locations in Zeeschelde 
Figure 3 shows the sediment transport for the different locations in the Zeeschelde. The sediment D50 ranges from very fine sand (near-bed "DBF") to very fine silt or mud (suspended "SUSP"). Sediment transport patterns are different for different locations, which is related to the position along the estuary and its position on the transect. For Driegoten the sediment transport shows a maximum 1 to 3 hours after low water. The sediment during this period is muddy, with a lot of flocs. Where the flow velocities in this period are low, the peak is probably related to the technique of the Delft Bottle: while this technique is suited for sand, it was found that during period with low flow velocities, currents through the bottle are insufficient to transport mud through the bottle, leading to anomalies in the measured transport.
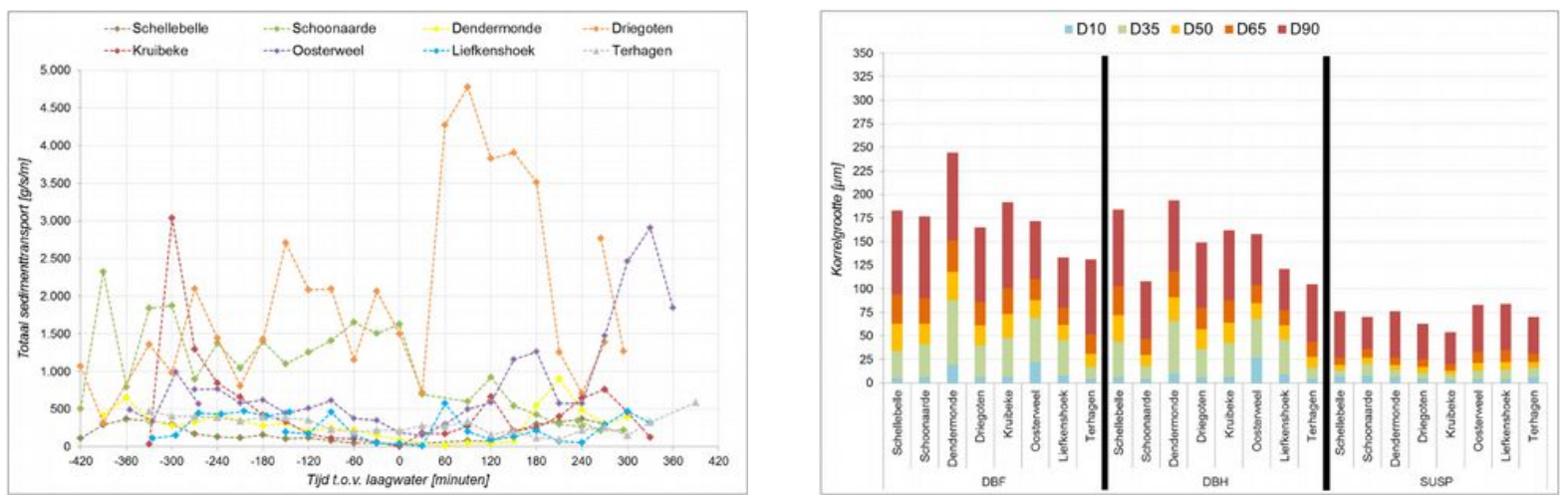

Figure 3- Overview of total sediment transport (left) and sediment characteristics (right) for locations in Zeeschelde

\section{ONGOING RESEARCH}

In 2015 the results of the measurement campaigns are further analysed. A first aspect focusses on the uncertainties of the results from the field measurements. Errors can be introduced during the execution of the measurements (e.g. Sediment capture during lowering and hoisting of bottle) as due to the technique (e.g. muddy sediments) and during the post-processing (e.g. Calculation of total transport). Possible errors are estimated resulting in error bars for the measurement results.

Next, a comparison is made between the measured transport rates and certain sediment transport formulas. A first exploratory comparison, based on the Bagnold approach, shows a rather good agreement for location Boom, while for other locations the agreement is worse.

Finally the measurement data are used the validate state-of-the-art numerical models. In the past, the models have been extensively calibrated and validated for hydrodynamics, but due to lack of available measurement data, sediment transport was never really validated. Sensitivity exercises have indicated the important influence of several numerical parameters. Preliminary results for the Beneden-Zeeschelde show a rather promising agreement (i.e. differences of factor 2 to 3 ), but further research is necessary and ongoing.

\section{REFERENCES}

Peters, J.J.; Cunge, J.A.; Plancke, Y.M.G. (2006). Role of practinioners and hydroinformatics in the decision-making process for morphological management of an estuary, in: Gourbesville, P. et al. (Ed.) (2006). Proceedings of the 7th International Conference on Hydroinformatics 2006, Nice, 4-8 September 2006. pp. [1-8]

Plancke, Y.; Vanlierde, E.; Taverniers, E.; Mostaert, F. (2012). Monitoring of physical parameters within the scope of the Dutch-Flemish integrated monitoring program, in: (2012). Hydraulic Measurements and Experimental Methods 2012 Conference (HMEM 2012), Snowbird, Utah, August 12-15, 2012. pp. [1-6]. 